\title{
Jornada de 30 horas semanais: condição necessária para assistência de enfermagem segura e de qualidade
}

Denise Pires ${ }^{1}$

Maria Goretti David Lopes ${ }^{2}$ Manoel Carlos Neri da Silva ${ }^{3}$ Jorge Lorenzetti ${ }^{4}$

Aceito para publicação em setembro de 2010

Este ensaio tem como objetivo resgatar justificativas técnico-políticas do movimento da enfermagem brasileira pela regulamentação da jornada de trabalho. Articula a teoria sociológica sobre profissão e trabalho com argumentos da prática assistencial, das políticas de saúde e da luta por condições de trabalho. Argumenta que a jornada de 30 horas é fundamental para fortalecer a enfermagem como profissão da saúde e condição necessária para a prestação de cuidados seguros e de qualidade. Conclui que a enfermagem tem significativa responsabilidade na assistência em saúde, o que requer condições de trabalho e conhecimentos científicos adequados para uma prática orientada por ideais de justiça social e direito à vida.

Descritores: Enfermagem, Trabalho, Jornada de Trabalho, Condições de Trabalho, Profissão.

\section{0-hours work per week: necessary condition for a qualified and safe nursing care services}

The objective of this essay is to present technical-political justifications of the Brazilian nursing movement towards regulating its workday. It articulates sociological theory concerning profession and labour with arguments about nursing practice, health care policies, and struggle for working conditions. We plead that a 30 hours workweek is fundamental to strengthen the nursing as health care profession and it is a necessary condition for a safe and qualified care. It concludes that nursing has significant responsibility in health care and requires adequate work conditions and scientific knowledge towards a practice guided by the values of social justice and the right to life.

Descriptors: Nursing, Work, Work Hours, Working Conditions, Profession.

\section{Jornada de trabajo de $\mathbf{3 0}$ horas por semana: condición necesaria para una atención de enfermería segura y de calidad}

El objetivo del presente ensayo es rescatar las justificaciones tecnicas y políticas del movimiento de la enfermería brasileña para la regulación de la jornada de trabajo. Se articula la teoría sociologica sobre profesión y trabajo con argumentos de la práctica asistencial, las políticas de salud y la lucha por las condiciones de trabajo. Se argumenta que la jornada de trabajo de 30 horas es fundamental para fortalecer la enfermería como profesión de la salud y para la prestación de una atención segura y de calidad. Se concluye que la enfermería tiene una responsabilidad importante en la atención de salud que requiere condiciones de trabajo y el conocimiento científico adecuado a la práctica guiada por ideales de justicia social y de derecho a la vida.

Descriptores: Enfermería, Trabajo, Horas de Trabajo, Condiciones de Trabajo, Profesión.

\section{INTRODUÇÃO}

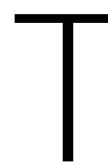

rata-se de uma reflexão sobre condições de trabalho com o objetivo de resgatar e analisar as justificativas técnico-políticas do movimento da enfermagem brasileira pela regulamentação da jornada de trabalho. O processo metodológico de construção do texto articula aspectos da teoria sociológica sobre profissão e trabalho com argumentos acerca da prática assistencial, das políticas de saúde e do processo histórico de luta da enfermagem brasileira por condições de trabalho. Defende que a bandeira das 30 horas é mais do que uma demanda corporativa; trata-se de um direito trabalhista, de justiça social e da defesa de uma política que interessa a toda a sociedade. Conclui com uma síntese da importância da jornada de 30 horas para profissionais e usuários dos serviços de saúde, assim como convoca os gestores em saúde a considerarem os benefícios para o setor, superando a visão imediatista de redução de custos.

1 Enfermeira. Doutora em ciências sociais - Unicamp. Professora do departamento de pós-graduação em enfermagem da Universidade Federal de Santa Catarina - UFSC Pesquisadora do CNPq. Presidente do Conselho Regional de Enfermagem - SC. E-mail: piresdp@yahoo.com.

2 Enfermeira. Presidente nacional da Associação Brasileira de Enfermagem - ABEn.

3 Enfermeiro. Presidente do Conselho Federal de Enfermagem - Cofen.

4 Enfermeiro. Professor do departamento de enfermagem da UFSC

5 Enfermeira. Técnica administrativa do departamento de enfermagem da UFPR. Diretora da ABEn Nacional.

6 Enfermeira. Presidente da ABEn-SC. 


\section{ENFERMAGEM: PROFISSÃO E TRABALHO DA SAÚDE}

A enfermagem como profissão tem a responsabilidade de tomar para si a definição das condições requeridas para o agir profissional seguro e de qualidade. A defesa das 30 horas semanais se coloca como um dos aspectos que fortalecem sua estruturação e seu reconhecimento como um grupo de características profissionais. Nesse sentido, enfrenta uma das fragilidades da profissão mencionadas pelos que a analisam sob o olhar da teoria clássica da Sociologia das Profissões ${ }^{(1-2)}$, que é a debilidade em relação à autonomia profissional. A teoria clássica tem sido contestada por autores da sociologia e da enfermagem, criticando sua utilização para hierarquizar grupos profissionais e mostrando os limites de seu uso como tipo ideal weberiano ${ }^{(3-4)}$. O referencial da sociologia das profissões contribui se empregado em uma perspectiva crítica e associado à teorização sobre processo de trabalho, incluindo na análise os macrodeterminantes históricos, sociais e institucionais, o que contribui para explicar o valor diferenciado atribuído aos diferentes profissionais ${ }^{(4-6)}$.

Considerando-se os atributos da enfermagem, ela "é uma profissão desenvolvida por um grupo de trabalhadores qualificados e especializados para a realização de atividades socialmente necessárias. Conta com entidades e organizações que a representam e que formulam regras para o exercício profissional, assim como a profissão dispõe de um código de ética que orienta o comportamento de seus agentes em bases moralmente aceitáveis". Produz e reproduz os conhecimentos que lhe dão competência para cuidar de seres humanos, do nascimento à morte ${ }^{(4,7-8)}$.

É importante considerar, também, que qualquer trabalho ocorre em sociedades históricas e que o trabalho da enfermagem é parte do trabalho em saúde. Nesse contexto, é influenciado pelo modelo hegemônico de sociedade e de ciência, pelas lutas políticas e pelas demandas que se expressam cotidianamente no cenário institucional.

No Brasil, a enfermagem é reconhecida pelo Conselho Nacional de Saúde como uma das profissões da saúde e está regulamentada pela lei 7498/1986. Trata-se de um trabalho essencial à vida humana e que está presente na quase totalidade das instituições que prestam assistência de saúde, sendo que, na rede hospitalar, está presente nas 24 horas de todos os 365 dias do ano ${ }^{(4)}$. Além da presença contínua nos serviços, constitui-se no maior grupo de profissionais da saúde, representando cerca de $60 \%$ nas equipes multiprofissionais ${ }^{(9)}$.

É uma força de trabalho expressiva e majoritariamente feminina. Em março de 2009, segundo o Conselho Federal de Enfermagem, os profissionais de enfermagem totalizavam, no Brasil, 1.243.804, sendo 178.546 enfermeiros (161.032 mulheres - 90,2\%), 466.985 técnicos em enfermagem (407.754 mulheres - 87,3\%) e 598.273 Auxiliares de Enfermagem (525.666 mulheres 87,8\%). Em outubro de 2010, o total de profissionais de enfermagem somava 1.500.335, sendo 224.708 enfermeiras(os) (15\%), 567.734 técnicas(os) de enfermagem (38\%), 648.567 auxiliares de enfermagem (43\%), 58.989 atendentes de enfermagem (4\%) e 337 parteiras (0,002\%).

A enfermagem desenvolve um trabalho essencial à vida, um trabalho especial de cuidado as pessoas para o bem viver e em situações de dor e sofrimento. No entanto, apesar do grande contingente numérico e da influência decisiva de seu trabalho na qualidade das ações de saúde, esse grupo profissional não dispõe, até hoje, no Brasil, de nenhuma proteção legal a seu trabalho.

Outras categorias profissionais da saúde já obtiveram conquistas em relação à jornada de trabalho, como médicos (20 horas semanais/quatro horas diárias, desde 1961), fisioterapeutas e terapeutas ocupacionais (30 horas semanais/ seis horas diárias desde 1994). Outro caso exemplar é o das assistentes sociais, que, no mesmo contexto histórico da reivindicação da enfermagem, em 3 de agosto de 2010, conseguiram aprovar no Congresso Nacional o projeto de lei $152 / 2008$, que estabelece a jornada de 30 horas, sancionado pelo presidente da República, Luiz Inácio Lula da Silva, em 27 de agosto de 2010.

\section{HISTÓRICO DA LUTA PELA JORNADA DE 30 HORAS SEMANAIS}

A luta dos profissionais de enfermagem pela definição de uma jornada de trabalho compatível com as características de seu trabalho já completa 55 anos. $O$ único veto ocorrido na primeira lei de regulamentação do exercício profissional da enfermagem, a lei 2604/1955, foi no artigo que estabelecia a jornada máxima de 30 horas semanais. No período recente, a enfermagem brasileira vem lutando há 11 anos pela aprovação do PL 2295/2000.

A importância e a necessidade dessa reivindicação vêm sendo reconhecidas em conferências de saúde, no Legislativo, no Judiciário, pelos meios de comunicação e pelas entidades que representam profissionais e usuários dos serviços de saúde.

Em 1993, a II Conferência Nacional de Recursos Humanos para a Saúde considerou que, pela natureza da atividade, a jornada máxima de trabalho para os profissionais dessa área deveria ser de 30 horas semanais. $\mathrm{Na} 12^{\mathrm{a}}$ Conferência Nacional de Saúde, na $3^{\text {a }}$ Conferência Nacional de Saúde do Trabalhador e na $3^{a}$ Conferência Nacional de Gestão do Trabalho e Educação na Saúde, foi deliberada a jornada de 30 horas para o setor. A Organização Internacional do Trabalho (OIT) afirma que a jornada de 30 horas é a mais adequada para profissionais de saúde e usuários dos serviços, o que foi ratificado pela Internacional de Serviços Públicos - ISP, Subregional Brasil, entidade sindical que representa oficialmente os(as) trabalhadores(as) do setor público na OIT, em nota de apoio às 30 horas para enfermagem ${ }^{(10)}$.

A Constituição Federal de 1988, inciso XIV, artigo 70, prevê “jornada de seis horas para o trabalho realizado em turnos 
ininterruptos de revezamento". Esse preceito, claramente aplicável ao trabalho da enfermagem em hospitais, está reconhecido no decreto $\mathrm{n}^{\circ} 4836$ de 9/9/2003, que alterou a redação do artigo $3^{\circ}$ do decreto $n^{\circ} 1590$ de 10/8/1995, estabelecendo como facultativo ao dirigente máximo do órgão ou entidade "da administração pública federal direta, das autarquias e das fundações federais" autorizar "os servidores a cumprir jornada de trabalho de seis horas diárias e carga horária de 30 horas semanais". Com base nesse decreto, o Ministério da Saúde baixou a portaria no 1281 de 19/6/2006, autorizando “a realização de jornada de trabalho de seis horas diárias e carga horária de 30 horas semanais" para os funcionários de unidades hospitalares sob sua gestão.

No entanto, o governo federal posicionou-se de forma contraditória em relação às 30 horas para a enfermagem. Enquanto o Ministério do Trabalho formalizou apoio ao PL 2295/2000, o Ministério da Saúde, que em 2006 autorizou jornada de 30 horas em hospitais sob sua gestão, em junho de 2010 emitiu nota técnica apoiando as 30 horas mas excluindo "os que trabalham em programas governamentais"(11). Uma posição inaceitável, especialmente porque caberia a esse Ministério defender o provimento das condições necessárias para a qualificação da assistência.

Em outubro de 2010, o empenho das entidades e as fortes mobilizações da enfermagem conquistaram a inclusão da reivindicação de regulamentação da jornada de trabalho na agenda das eleições para a presidência da República, com posicionamento favorável dos candidatos que disputavam o segundo turno. Nesse novo cenário, aumentam as possibilidades de aprovação do PL 2295/2000 ainda nessa legislatura. Perdem os interesses dos empresários da área da saúde e ganham os profissionais de enfermagem e a sociedade brasileira.

\section{JORNADA DE 30 HORAS NÃO É PRIVILÉGIO}

A luta pela regulamentação da jornada de trabalho em no máximo 30 horas semanais e seis horas diárias, no contexto na Lei do Exercício Profissional, fortalece a enfermagem como profissão e conclama a sociedade a reconhecer que se trata de um trabalho que precisa de condições especiais para uma prática segura.

O trabalho da enfermagem, de convívio com dor, sofrimento e doença, turnos ininterruptos, sábados, domingos e feriados, más condições de trabalho, muita responsabilidade e pouca valorização, tem levado à insatisfação, ao adoecimento e ao aumento da evasão profissional. A literatura é farta em registros dos índices alarmantes de absenteísmo no trabalho da enfermagem e de sua forte relação com o adoecimento desses profissionais ${ }^{(12-14)}$.

A redução da jornada de trabalho da enfermagem contribuirá para diminuir o desgaste físico e emocional e os riscos decorrentes desse trabalho, que se agravam por sua condição feminina, que associa às atividades do espaço público o cuidado dos filhos e do ambiente doméstico.

Não se trata de defesa de privilégios, mas do direito de a população ser atendida por profissionais competentes e saudáveis. Assistência segura e de qualidade, além de moralmente requerida, é mais econômica, pois evita danos e reduz ações judiciais contra os serviços de saúde. Instituições públicas e privadas passarão a gastar menos com as faltas ao trabalho por adoecimento dos profissionais de enfermagem.

\section{A questão do duplo emprego - um falso argumento para manter uma injustiça}

$\mathrm{Na}$ história, a reivindicação de jornadas compatíveis com o trabalho sempre disse respeito à proteção dos trabalhadores, nunca foi motivada pela busca de um novo emprego. No caso da enfermagem, não é diferente.

As vozes contrárias ao projeto 2295/2000, de diversos matizes ideológicos, têm usado o argumento de que a jornada de 30 horas vai resultar no duplo emprego, como se os profissionais de enfermagem reivindicassem uma jornada menor para assumir um novo emprego e não para cuidar de si e dos outros com segurança.

Trata-se de um argumento claramente ideológico. Primeiramente, porque a existência de duplo emprego atingindo até 88 horas semanais (duas vezes as 44 horas semanais da (LT) não mobilizou nenhuma reação protetora por parte dos gestores e legisladores. Com certeza, trabalhar 60 horas semanais seria muito.

Mas, ironicamente, trabalhar 88 horas semanais para sobreviver às remunerações ínfimas não parece ser um problema.

Em segundo lugar, porque o direito a ter mais de um emprego é constitucional ${ }^{(15)}$ e não há reação nem críticas ao duplo emprego de médicos, dentistas, fisioterapeutas, entre outros profissionais de saúde. Por que o questionamento é somente para a enfermagem?

Em terceiro, as lideranças de enfermagem têm defendido uma jornada máxima de 30 horas com salário digno, incluindo a possibilidade de o trabalhador optar por dedicação exclusiva, o que beneficiaria profissionais e usuários.

\section{Impacto financeiro das $\mathbf{3 0}$ horas: o que realmente está em jogo?}

Empregadores do setor privado de saúde e setores do governo vêm alegando que a redução da carga horária dos profissionais de enfermagem, pelo enorme impacto financeiro, traria sérios prejuízos. No entanto, as evidências mostram a inconsistência desse argumento.

Em primeiro lugar, o impacto no orçamento da União é 
praticamente nulo, uma vez que a maioria dos profissionais de saúde do Sistema Único de Saúde (SUS) é remunerada pelos estados ou municípios, com exceção dos hospitais universitários (HU), pagos pelo MEC. Além disso, parcela significativa da rede pública estadual e dos HU de vários municípios, assim como hospitais privados de boa qualidade, já adotam as 30 horas.

$\mathrm{Na}$ atenção básica, destaca-se a Estratégia Saúde da Família - ESF, que estabeleceu a jornada de trabalho de 40 horas semanais ${ }^{(16)}$. Essa realidade tem sido utilizada como argumento impeditivo para a implantação das 30 horas para os profissionais de enfermagem. No entanto, os médicos têm jornada legal de 20 horas semanais, e não houve qualquer impossibilidade para sua contratação na ESF, nem a ESF foi inviabilizada. Para garantir o atendimento da população adscrita na perspectiva da integralidade e da interdisciplinaridade, nas oito horas diárias ou até com a desejável ampliação do horário de atendimento, muitas opções são possíveis. Uma delas é o aumento da contratação de profissionais de enfermagem com um pequeno investimento; outra é a reorganização do processo de trabalho, praticamente sem custo.

Em segundo lugar, aumentar o investimento em saúde é necessário e desejável. No Brasil, o gasto público no setor é muito inferior ao dos países da Organização para Cooperação e Desenvolvimento Econômico (OCDE) (Brasil: 8,4\% do PIB em saúde, sendo apenas $41,6 \%$ de investimento público - IBGE, 2007; países da OCDE: em média $8,9 \%$ do PIB, sendo $73,2 \%$ de investimento governamental - OCDE, 2007).

Além disso, estudo do Departamento Intersindical de Estatística e Estudos Sócio-Econômicos (Dieese) ${ }^{(17)}$ mostrou que, com a implantação das 30 horas, o aumento médio nas ocupações de enfermagem seria de $26,26 \%$ e o impacto no custo total de rendimentos pagos aos empregados no setor saúde, de $1,26 \%$. Mais emprego contribui para aquecer o mercado interno e melhorar o desempenho da economia, o que, somado aos resultados positivos da economia brasileira nos últimos anos, resultará em mais recursos a serem aplicados em saúde pela União e pelos estados e municípios. O financiamento da saúde, conforme a Emenda Constitucional 29/2000, é composto de verbas do orçamento da União (no mínimo igual ao do ano anterior mais o crescimento do PIB), além de $12 \%$ da receita dos estados e de $15 \%$ da arrecadação dos municípios. Portanto, se a economia continuar crescendo, automaticamente crescem os recursos destinados à saúde.

Considerando-se o valor dos custos face ao impacto positivo da medida para o setor, justifica-se plenamente a adoção das 30 horas para a enfermagem.

\section{CONSIDERAÇÕES FINAIS}

$O$ fato de a enfermagem ter enorme participação nas ações de saúde deve servir como forte motivo para sua valorização, e não para um tratamento discriminatório. A saúde tem aparecido como o principal problema para os brasileiros e a enfermagem constitui-se em força imprescindível para seu enfrentamento. A consolidação do SUS nos próximos anos precisa e depende da enfermagem.
A defesa de condições de trabalho está diretamente associada à responsabilidade dessa profissão com a qualidade e a segurança dos cuidados prestados.

Cabe às entidades representar a enfermagem na sociedade, atuando para fortalecê-la como profissão da saúde, definindo regras e parâmetros legais e éticos para o exercício profissional e defendendo sua aplicação prática.

\section{FATOS E FOTOS - ENFERMAGEM BRASILEIRA EM LUTA PELAS 30 HORAS}

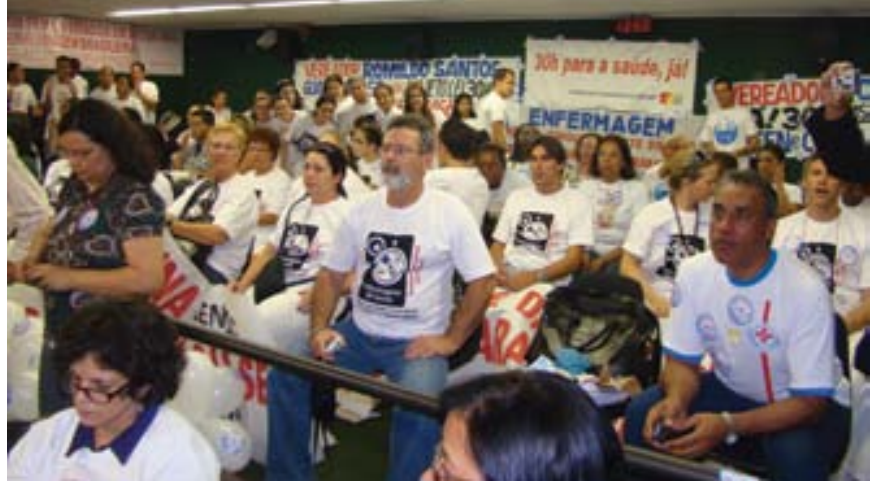

Mobilização da enfermagem brasileira pelas 30 horas, Brasília, 25/3/2009

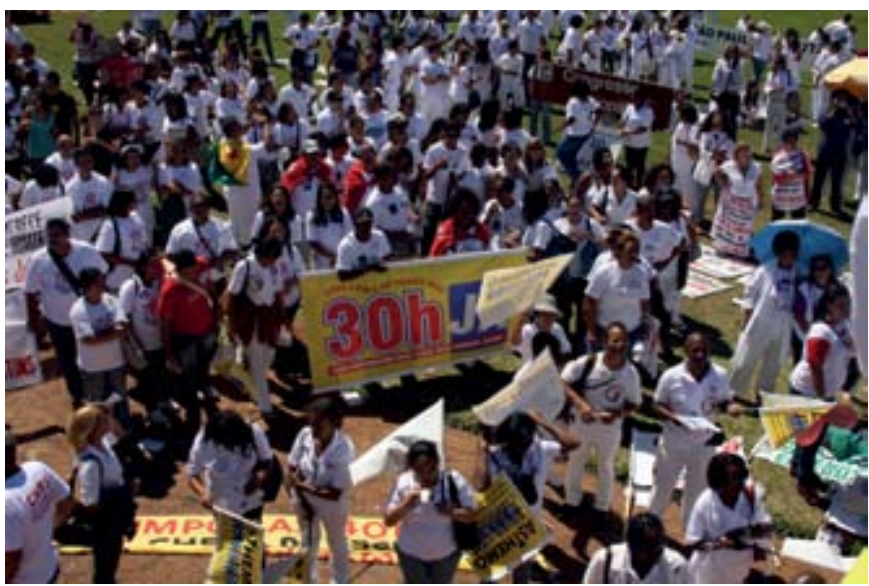

Mobilização da enfermagem brasileira, Brasilia, 16/4/2010.

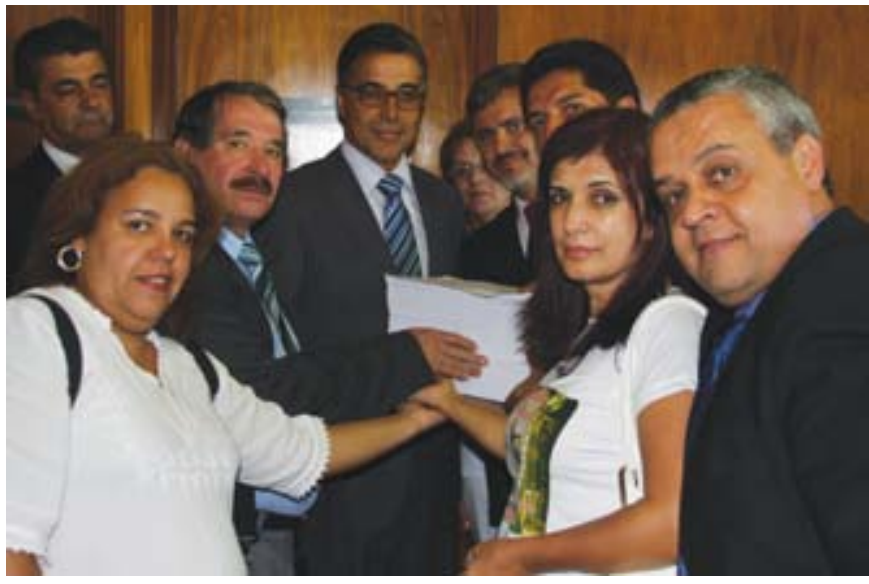

CNTSS, CNTS, FNE e o secretário geral do Cofen entregam abaixo-assinado pelas 30 horas no Congresso Nacional, Brasília, 16/4/2010. 


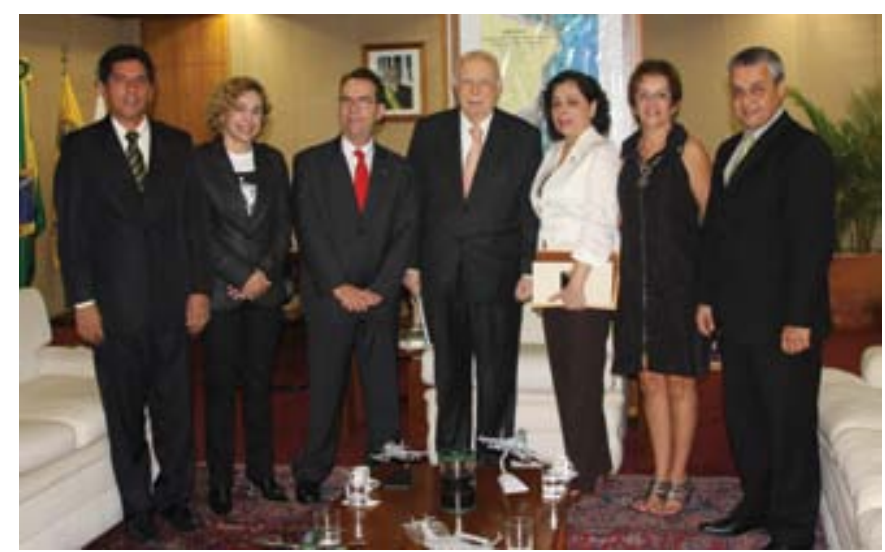

Lideranças da enfermagem brasileira com o vice-presidente da República. Da esquerda para a direita: primeiro tesoureiro do Cofen, Antônio Marcos Freire Gomes; deputada Ana Paula Lima (PT/SC); deputado Décio Lima (PT/SC); vicepresidente da República, José Alencar; presidente da ABEn Nacional, Maria Goretti David Lopes; presidente do Coren/SC, Denise Pires; primeiro secretário do Cofen, Gelson Albuquerque, Brasília, 16/4/2010.

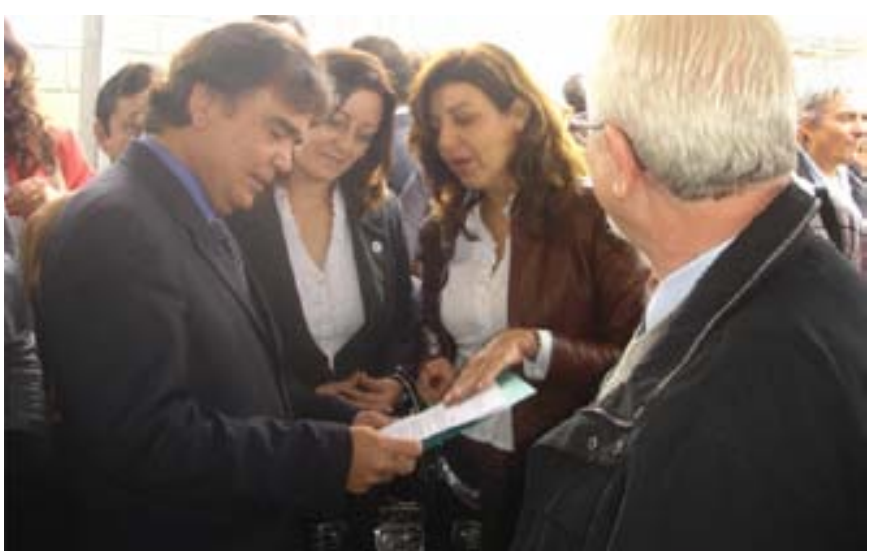

A secretária do Coren/SC, Felipa Amadigi, e a diretora da ABEn/SC, Márcia Delcastanhel, entregam documento das 30 horas ao ministro da saúde, José Gomes Temporão, Florianópolis, 12/8/2010.

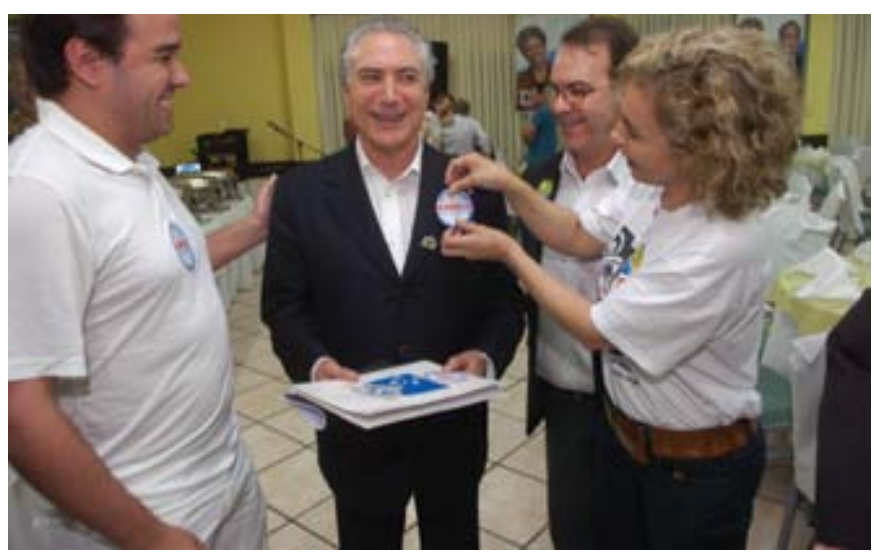

Conselheiro do Coren/SC, Gabriel Luckmann; deputada Ana Paula Lima (PT) SC); deputado Décio Lima (PT/SC); presidente da Câmara, Michel Temer (PMDB/SP), Blumenau, 27/8/2010.

\section{Referências}

1. Machado MH. Profissões de saúde: uma abordagem sociológica. Rio de Janeiro: Fiocruz; 1995.

2. Machado MH, Rego S. Essencialidade da profissão médica e serviços de saúde [Internet]. [citado em 2010 Jun 15]. Disponível em: http://www.fundap.sp.gov.br/publicacoes/ cadernos/cad19/Fundap19/ESSENCIALIDADE DA PROFISSAO

\section{MEDICA E SERVICOS DE SAUDE.pdf.}

3. Durand JCG. A serviço da coletividade: crítica à sociologia das profissões. Rev Adm Pública. 1975.

4. Pires D. A enfermagem enquanto disciplina, profissão e trabalho. Rev Bras Enferm. 2009;62(5):739-44.

5. Peduzzi M. Equipe multiprofissional de saúde: conceito e tipologia. Rev Saúde Pública. 2001;35(1):103-9.

6. Fourez G. A construção das ciências: introdução à filosofia e a ética das ciências. São Paulo: Unesp; 1995.

7. Pires D. Hegemonia médica na saúde e a enfermagem. São Paulo: Cortez; 1989.

8. Pires D. Reestruturação produtiva e trabalho em saúde no Brasil. 2a ed. São Paulo: AnnaBlume/CNTSS; 2008.

9. Ministério do Trabalho e Emprego (BR). Relação Anual de Informações Sociais/Rais. Brasília: Ministério do Trabalho; 2008.

10. Public Services International Sub Regional Brasil. Ao Congresso Nacional: 30 horas já! São Paulo; 2010.

11. Ministério da Saúde (BR). Nota técnica 334/2010. Brasília: Ministério da Saúde; 2010.

12. Nascimento GM. Estudo do absenteísmo dos trabalhadores de enfermagem em uma unidade básica e distrital de saúde do município de Ribeirão Preto, SP [dissertação]. Ribeirão Preto: EERP-USP; 2003.

13. Silva DMPP, Marziale MHP. Absenteísmo de trabalhadores de enfermagem em um hospital universitário. Rev Latinoam Enferm. 2000;8(5):44-51.

14. Faria $A C$, Barboza DB, Domingos NAM. Absenteísmo por transtornos mentais na enfermagem no período de 1995 a 2004. Arq Ciênc Saúde. 2005;12(1):14-20.

15. Presidência da República (BR). Casa Civil. Emenda Constitucional n 34 de 13 de dezembro de 2001. Brasília: Casa Civil; 2001.

16. Ministério da Saúde (BR). Portaria n 648/2006. Brasília: Ministério da Saúde; 2006.

\section{Departamento Intersindical de Estatística e Estudos}

Socioeconômicos. Escritório Regional do Distrito Federal. A redução da jornada de trabalho dos profissionais de enfermagem. Brasília: Dieese; 2010. 